\title{
Uma conversa com o artista guineense Nú Barreto
}

Virginia Maria Yunes ${ }^{1}$

\footnotetext{
1 Virginia M. Yunes - Fotógrafa, graduada e doutora em Artes Visuais pela Universidade do Estado de Santa Catarina (UDESC), onde atualmente leciona Fotografia como professora colaboradora. Possui vasta experiência como fotógrafa documentarista, tendo feito parcerias com instituições, mídias e ONGs. Realizou diversas exposições nacionais e internacionais. Desenvolve pesquisas nas áreas de Arte, Fotografia, Cultura africana e afro-brasileira.

e-mail: vyunes@gmail.com

Currículo lattes: http://lattes.cnpq.br/9819712901436705

ID Orcid: https://orcid.org/0000-0001-8780-5327
} 


\title{
Resumo
}

O artista plástico Manuel Jerónimo Barreto da Costa Oliveira, conhecido como Nú Barreto, nasceu no ano 1966 em São Domingos, norte da Guiné-Bissau, país da Costa ocidental africana. Aos 21 anos parte para Paris, onde ainda reside e trabalha. Considerado uma das principais figuras da senda africana contemporânea, suas obras constam de diversas coleções privadas e museus e já foi exibida em diversas exposições, individuais ou coletivas, mundo afora ${ }^{1}$. Artista multidisciplinar apresenta sua arte de forma hibrida, combinado os mais diversos materiais e técnicas das diversas linguagens: desenho, fotografia, pintura e vídeo. Ele incorpora em sua estética a formas, símbolos e arquétipos das cores e motivos, com forte significado para denunciar a desumanização, a desvalorização do indivíduo, a miséria e o sofrimento que assola, não somente o continente africano, o mundo.

\section{Palavras-chave}

Nú Barreto, Guiné-Bissau, Artista Plástico, Arte Contemporânea em Diáspora.

\begin{abstract}
O artista plástico Manuel Jerónimo Barreto da Costa Oliveira, conhecido como Nú Barreto, nasceu no ano 1966 em São Domingos, norte da Guiné-Bissau, país da Costa ocidental africana. Aos 21 anos parte para Paris, onde ainda reside e trabalha. Considerado uma das principais figuras da senda africana contemporânea, suas obras constam de diversas coleções privadas e museus e já foi exibida em diversas exposições, individuais ou coletivas, mundo afora . Artista multidisciplinar apresenta sua arte de forma hibrida, combinado os mais diversos materiais e técnicas das diversas linguagens: desenho, fotografia, pintura e vídeo. Ele incorpora em sua estética a formas, símbolos e arquétipos das cores e motivos, com forte significado para denunciar a desumanização, a desvalorização do indivíduo, a miséria e o sofrimento que assola, não somente o continente africano, o mundo.
\end{abstract}

\section{Keywords}

Nú Barreto, Guiné-Bissau, Artista Plástico, Arte Contemporânea em Diáspora.

\section{Resumen}

El artista plástico Manuel Jerónimo Barreto da Costa Oliveira, conocido como Nú Barreto, nació en 1966 en São Domingos, al norte de Guinea-Bissau, un país de la costa de África occidental. A los 21 años se muda a París, donde aún vive y trabaja. Considerado una de las principales figuras de la trayectoria africana contemporánea, sus obras forman parte de varias colecciones privadas y museos y ha sido expuesta en varias exposiciones, individuales o colectivas, alrededor del mundo. Artista multidisciplinar presenta su arte de manera híbrida, combinando los más diversos materiales y técnicas de diferentes lenguajes: dibujo, fotografía, pintura y video. Incorpora en su estética las formas, símbolos y arquetipos de colores y motivos, con un fuerte significado para denunciar la deshumanización, la devaluación del individuo, la miseria y el sufrimiento que azota, no solo al continente africano, al mundo.

1 Portugal, Espanha, França, Bélgica, Alemanha, Suíça e Suécia, China, Dubai, Senegal, Mali, Costa do Marfim, Togo, Burkina Faso, Angola e África do Sul, Brasil e Nova lorque. 


\section{Revista Apotheke}

\section{Palabras clave}

Nú Barreto, Guinea-Bissau, Artista Plástico, Arte Contemporánea en Diaspora.

ISSN: 2447-1267 


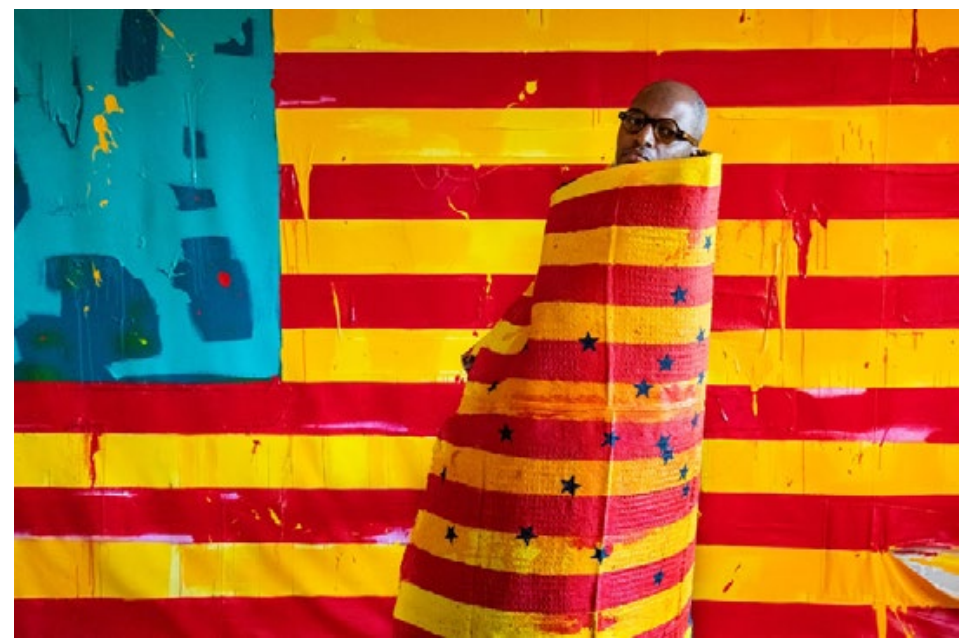

Figura 1: Nú Barreto envolto em sua bandeira, 2018, fotografia. Foto: Thierry Caron/Divergence (Cortesia Nú Barreto)

A ideia da "diáspora negra", segundo Paul Gilroy (2001) é um conceito que abre novas possibilidades para se pensar a territorialidade e as formas de conceber pertencimentos e fronteiras culturais. A arte é um importante lugar para investigar e discutir as identidades situadas no marco da contemporaneidade. Como é a sua experiência enquanto artista africano na diáspora?

A minha experiência como artista africano na diáspora, precisamente na França, onde vivo e trabalho desde 1989, não se diferencia muito das experiências dos outros artistas. Embora haja diferenças entre as histórias particulares de cada um, a luta pela visibilidade do trabalho é a dificuldade maior que nos artistas encontramos. É muito difícil e complexo singrar no circuito europeu, apesar de hoje haver maior flexibilidade e abertura à diferença, aos estrangeiros, os desafios inerentes à aceitação do Outro, não desaparecem completamente. Devo ao meu percurso a minha posição atual, às minhas experiências, enquanto africano na diáspora, que sobrepõe dificuldades, resistências e perseverança. Hoje, vivo do meu trabalho e colaboro com a Galerie Nathalie Obadia, uma galeria de arte contemporânea, que conta com dois espaços em Paris e um em Bruxelas. Percebo que o caminho é longo, todavia, vale a pena! Como costumo dizer: "Viver da Arte é uma Arte".

Conte sobre sua trajetória como artista. Quais os principais desafios que você vivenciou ao longo da sua carreira?

O desenho sempre esteve presente na minha família, tanto da parte materna 
quanto paterna, por isso, assumi esta prática ainda criança. Reconheço o privilégio de abraçar profissionalmente a carreira de artista e agradeço o destino! Aos 20 anos, quando um irmão faleceu, parei de desenhar, e curiosamente me interessei pela fotografia. Um amigo me presenteou com a minha primeira câmera fotográfica, mas, logo pus a arte de lado e continuei a levar a minha vida como podia. Um ano depois, fui para França, a convite do meu tio, para estudar Engenharia Informática, mas, depois dos três primeiros anos no estrangeiro, as coisas não corriam da maneira como eu havia sonhado. O bichinho da arte voltou, e, me fez lembrar do nosso amor. Abandonei a formação em Informática, escolhi a arte e decidi ganhar a minha liberdade. Tal vontade e determinação não foi do agrado do meu tio. Iniciei os meus estudos em fotografia na École Nationale des Métiers de L'Image des Gobelins e trabalhava como assistente em fotografia de moda, para ganhar o meu sustento. Voltei a desenhar e aos poucos comecei a pintar. À medida que recebia convites para expor o meu trabalho, fui evoluindo e abraçando outros projetos que me abriram portas no âmbito das artes.

\section{Temáticas como a desigualdade e a exclusão são centrais na sua obra. 0 que inspira/motiva você e que mensagem procuras transmitir?}

Todo meu trabalho está relacionado com problemáticas sociaise o comportamento dos "Seres" ditos "Humanos". Não tenho o hábito de chamar os Homens de "Seres humanos", mas sim, de "Seres a humanizar". De acordo com a minha ideologia, o Homem é, humano por intermitência, por ser imperfeito. O conceito de Humanidade é muito pesado para ser atribuído a um ser imperfeito. Engloba muita amabilidade e outras vertentes. Meu papel como artista, consiste em evidenciar as duras realidades que, a sociedade expõe sem hesitação e, aparentemente, sem constrangimento. Daí a transposição para as telas e demais suportes usados. Minhas obras são como janelas para o mundo, testemunhos da história de um povo ou de uma sociedade, que, embora não tenham uma leitura "fácil", o essencial é compreendido e acredito poder tocar na alma das pessoas. Não é uma questão de escolha pessoal, é por não compactuar com a situação atual do mundo. Temos que trabalhar de mãos dadas, em sintonia, contra tantas desigualdades e exclusões que assolam a sociedade.

\section{Por muito tempo, o Ocidente quis e esperou do artista estrangeiro, vindo de países ditos subdesenvolvidos, um estilo primitivista, exótico, que retratasse a sua cultura, não permitindo a este a abordagem de outros temas. Qual a sua opinião sobre isto?}

Sobre o critério do Ocidente, impor e esperar um certo exotismo nas expressões artísticas dos africanos, creio que cabe aos mesmos erradicar essa ideologia e propor 
a realidade em que vivem. A aceitação desta ditadura artística acontece, em alguns casos, devido à necessidade de sobrevivência do artista. Existe uma fina supremacia de uma cultura a dominar a outra. A falta do enquadramento e de uma política cultural, criou ou cria ainda, muitas dificuldades para os artistas, que, permitem tais influências e facilidade. É grave. $O$ artista deve extinguir essa problemática, a não compactuar com o que não o liberta, para poder uma evolução independente. Assim, como o resto do mundo não impõe ao Ocidente uma outra visão da sua cultura, nem da sua arte, também o Ocidente não deveria intrometer-se numa visão alheia, que deforma, e desajusta a realidade do Outro. É um caso de extrema relevância.

\section{Ainda que radicado em Paris há tanto tempo, parece ser que suas raízes na África Ocidental influenciaram, e ainda influenciam, o seu trabalho.}

Não posso me abstrair do africano, ou guineense, que sou. Serei sempre africano, e, orgulho-me das minhas raízes. É uma riqueza. A minha africanidade se exprime em tudo quanto me revela. Por outro lado, um artista não deveria estar fechado a nenhum espaço geográfico determinado. Sendo "revolucionários", preocupamos com as dificuldades do mundo fora, e não só do lugar onde nascemos ou nos encontramos. Por eu ser um indivíduo imperfeito, em estado de humanização, não um humano completo, devo me preocupar com as pessoas que, tal como eu, fazem parte do mundo, isso me faz sentir útil. Não posso, não quero, nem me vou esconder por detrás do africano, do guineense, limitando-me.

\section{Você costuma dizer: "Esta é a minha Guiné, a Guiné que tenho comigo!", como sendo o lugar que habita todas suas memórias e experiências. Qual a importância desse lugar no seu ato criativo?}

Adoro a Guiné, a minha cultura, e conforta-me o fato de conseguir guardar dentro de mim este legado, que passa também para as obras que crio. Uso palavras, ditados, provérbios do meu crioulo, porque me ajuda a interpretar os fatos da vida. Incorporo nas telas palavras, expressões e textos escritos à mão. $\bigcirc$ crioulo continua a ser uma fonte de inspiração. Não obstante, ser guineense não me impede de absorver parte das outras culturas, através das viagens que faço.

\section{Como se dá o seu processo criativo?}

O meu processo criativo é aleatório. Não tenho um tempo determinado para acabar uma obra, pode durar um dia, meses e até anos. Depende do grau de 
complexidade da obra, do tamanho da peça e do seu conteúdo, também, da etapa da vida em que me encontro. Continuo o meu processo criativo até entender que já dei volta ao assunto. Considero-me um artista multidisciplinar, costumo trabalhar em grandes formatos onde combino o desenho, a pintura, a fotografia, objetos e colagem. Tenho por hábito recuperar objetos que encontro na rua dando-os uma segunda vida nas minhas obras, que eu chamo de RR (Reciclar e Restituir). Há muito tempo eu não uso tinta a óleo por razões de saúde. A inalação constante me afetou bastante, pelo que acabei por desistir, e hoje, percebendo a longevidade da tinta acrílica, fico satisfeito. Voltarei usá-la em um projeto futuro, com obras de outras dimensões.

Suas obras são caracterizadas pela presença de vários elementos simbólicos, entre eles, as cores. $O$ vermelho, por exemplo, é uma cor recorrente. $O$ que representa, para si, esta escolha cromática?

A minha relação com a corvermelha foi desde sempre. Não a uso por conveniência, mas por pertinência. Interpreto a sociedade na qual vivo, usando o vermelho para tudo aquilo que não consigo retratar, descrever, desenhar. As eloquências e euforias dos ditos Seres Humanos. A única cor que possuí, na minha perspectiva, duas vertentes emotivas: a tristeza e a alegria, respondendo, às minhas inquietações e preocupações face à sociedade. Todas as cores possuem a sua própria força, mas. Quando uso o azul ou o preto o impacto é desigual. $\bigcirc$ vermelho passou a ser uma referência à minha pessoa, é a minha assinatura. A cor da vida.

Para retratar a humanidade, que nas suas telas surgem sob a forma de figuras que caem do céu, ora livres, ora abandonadas, você costuma recorrer a uma expressão, que diz: "Somos largados como se fossemos o pólen das flores, que é levado pelo vento". Fale mais sobre isso.

É um proverbio guineense, que consiste em tratar as pessoas abandonadas como se fossem o pólen no ar, que voa conforme o vento. Procuro sempre estar perto da minha tradição, buscando nela elementos para a minha expressão artística. As personagens dispersas no espaço, parecem numa cena de queda, ora subindo ora caindo, elas representam pessoas abandonadas, lutando por si, cada uma buscando a salvação. Tais personagens são teratológicos, ou seja, apresentam deformações morfológicas, simbolizando suas imperfeições, assim como os "ditos Seres Humanos" imperfeitos com a sua humanidade em construção. Para refletir a humanidade é imperativo repensar o individualismo exacerbado dos Homens.

Sobre a série Funguli, a que se deve a escolha do conceito? Porquê optou 


\section{pelo 'branco', 'cinzento' e 'negro'?}

Neste projeto fui ao encontro, mais uma vez, da minha tradição, da minha cultura, das minhas dores, das minhas preocupações. A palavra "Funguli", na língua Mandinga, significa "esbranquiçado", referente a pele seca ou acinzentada que a pele negra assume em determinados indivíduos, que pela sua aparência são taxados de inferiores, e associados à pobreza. O conceito por trás da palavra "Funguli", na tradição da Guiné-Bissau, visa classificar e separar as classes sociais, de acordo com esta marcação de cinza na pele. A vida de um artista é igual a todas as pessoas. Sempre pontuada com algo que nos marca e nos toca. A mim toca-me bastante a questão da separação. Não vejo razão para haver separação e divisão de classes, porque somos todos iguais. Parto sempre do princípio de que "nada levamos desta vida", como dizia a minha mãe. Deixamos tudo nesta terra. Não vale a pena tanta cobiça, tantas guerras. É esse "grito" que tentei transpor nas minhas telas contra aqueles que apontam para o Outro, dizendo: "és pobre", "és inferior a mim", "não és humano como eu". A série é composta por ora de quatro pinturas.
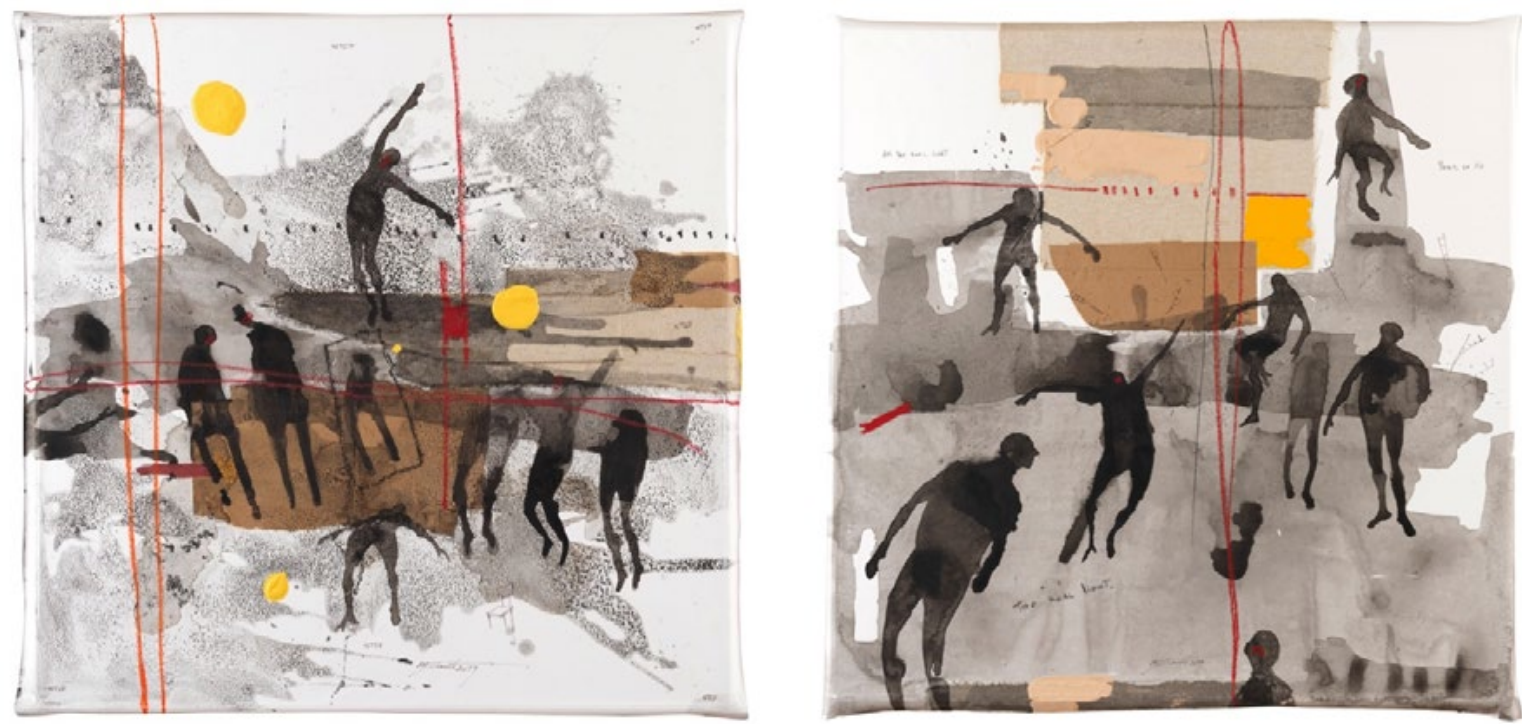

Figura 2 (esquerda): "Imapasse" e figura 3 (direita): "Proud Of Me", ambas da Série "Funguli", 2019, técnica mista: acrílico, tinta nanquim, colagem, marouflage, 95 × 95 cm, obra de Nú Barreto. Foto:

Atelier 80/Paris (Cortesia Nú Barreto)

\section{Uma outra série intulada "Homens Imperfeitos" percebo que as silhuetas são pintadas em cor vermelha. Fale-me da simbologia inerente a esta escolha.}

Esses seres contorcidos, amputados, levitando, são personagens que gritam as 
dores que o mundo sofre. A série retrata uma viagem pela solidão de figuras humanas destinadas a imperfeições crônicas, num mundo desenhado a vermelho-sangue e cravado de símbolos aparentemente quotidianos. São colagens em papel e desenhos com lápis de cerâmica.

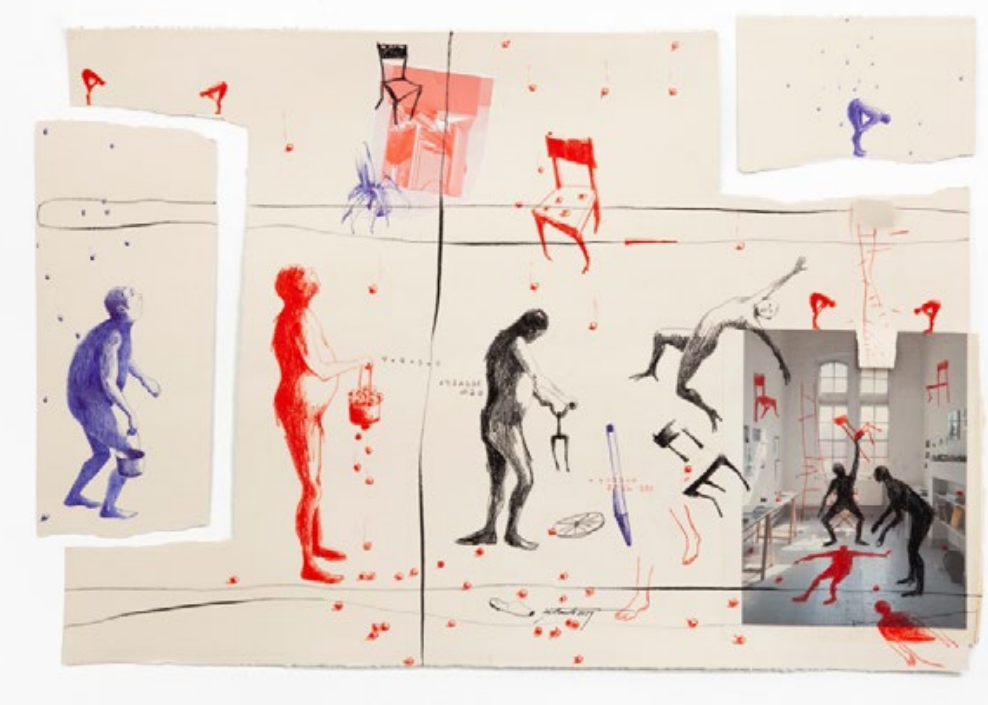

Figura 4: Nú Barreto, "Que Reste-t-il?", série: "Homens Imperfeitos", 2019, técnica: lápis cerâmica, caneta e colagem sobre papel, 85 × 122,3 cm de Nú Barreto. Foto: Atelier 80/Paris (Cortesia: Nú

Barreto)

\section{Existe algum trabalho que lhe tenha causado um desafio maior?}

O trabalho mais desafiador, para mim, foi a obra que intitulei: "Estados Desunidos de África" (2009). Trata-se de uma série de nove pinturas (até agora), cada uma retratando uma bandeira. Usei como referência a bandeira americana, mas, inverti a palavra Unidos por Desunidos, substitui as cores americanas pelas cores usadas majoritariamente nas bandeiras africanas: verde, vermelho, amarelo e preta. A obra é composta de 54 estrelas negras, cada uma corresponde aos 54 países do continente africano. Todas elas espalhadas pela tela, colocadas de forma desordenada, para simbolizarem a desordem gerada pelos conflitos entre os Estados. O conjunto destinase a evocar um continente que enfrenta a sua herança, por vezes, sangrenta, assim como as sequelas das descolonizações, e posterior divergência política nos diferentes países africanos. A ideia (utópica) de um grandioso projeto, intitulado Estados Unidos de África, foi um sonho dos pan-africanistas, que culminou em algumas tentativas arduamente executadas, em vão. Esta é uma preocupação profunda minha, que me assombra e alarma, e pela qual empolgo a sociedade em geral, que se questione e se revele proativa. Assim surge bandeira sob título "Yako", do termo "Akan", originário 
da Costa do Marfim, que significa: "ter empatia com a dor", está pontilhada de encaixes que perfuram a tela, e expressam as guerras e os diversos golpes de estado ocorridos ao longo do século XX. Da mesma forma, "Ossatura", onde o uso de ossos enfatiza a violência ocorrida, condenando os genocídios. "Vandalisme Coloré" é uma das nove bandeiras, espetada com uma infinidade de alfinetes tal qual uma boneca de vodu, testemunhando a dor e os estigmas, que perduram, das populações africanas. Porém, há uma mensagem de esperança nesta série de bandeiras, porque a África é, também, ela um reservatório de otimismo. Apesar das dificuldades e das feridas abertas, destaco os recursos intelectuais e culturais de que as nações africanas dispõem, ainda assim. Desta feita, na bandeira "La Source (A Fonte)", livros de autores africanos, sem distinção da cor, da raça e do género, estão suspensos na tela.
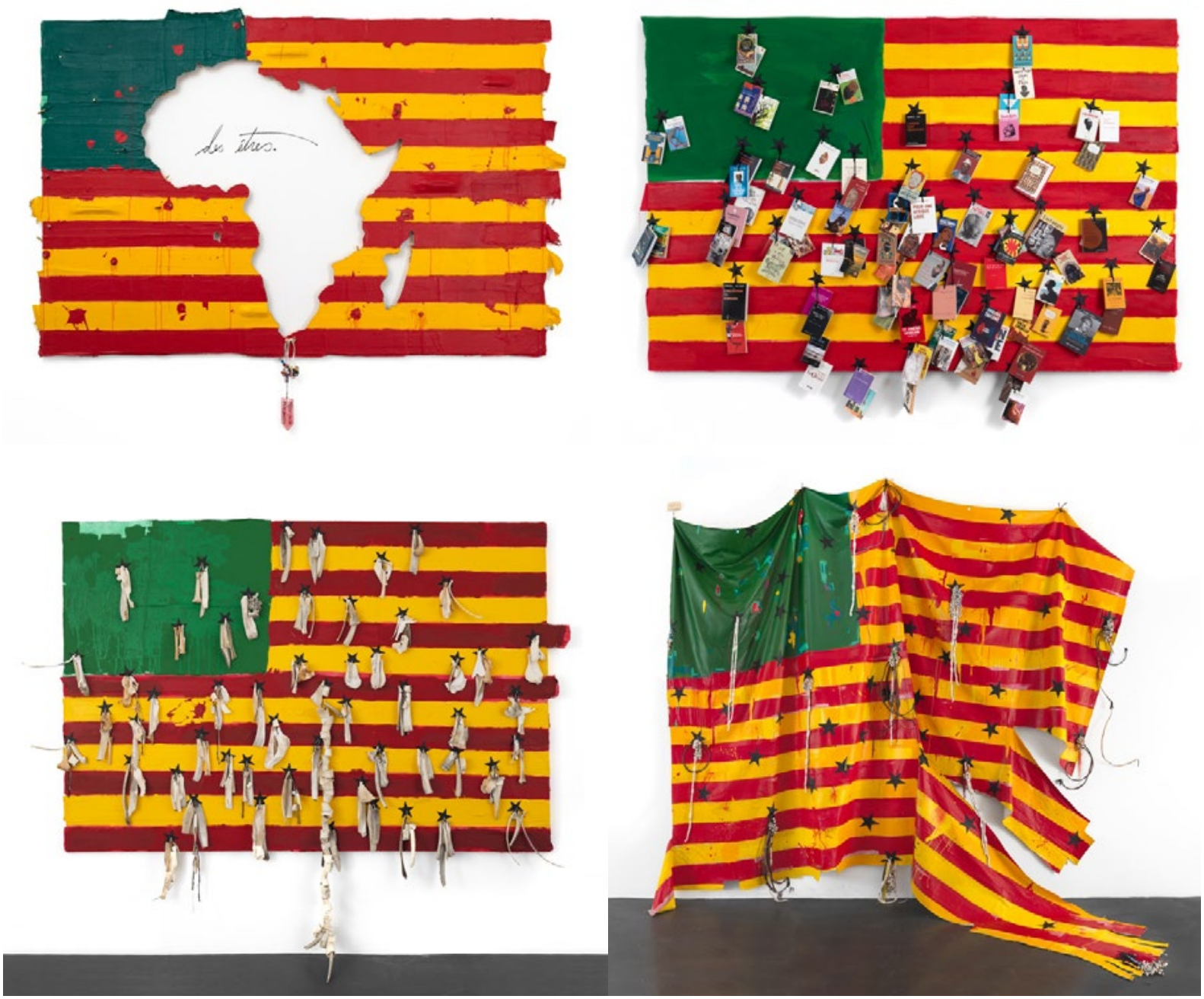

Figura 5: Nú Barreto, série "Estado Desunidos da África": à esquerda-superior: "Eventré", à direitasuperior: "La Source", à esquerda-inferior: "Ossements" e à direita-inferior: "Ça Va Aller", 2018. Técnica: Acrílico, objetos diversos, tela/contraplacado. Foto: Atelier 80/Paris (Cortesia: Nú Barreto \& Galerie Nathalie Obadia) 
artística. Qual é a importância deste tipo de experiência para os artistas?

Visitei o Brasil pela primeira vez em 2015, para participar numa residência artística sob a temática os "Rastros", na cidade de Vitória (Espírito Santo). Foi uma grande oportunidade que me permitiu o encontro com outro povo e cultura distinta, a partir do qual alarguei os meus horizontes. Estes intercâmbios oferecem aos artistas a possibilidade de trocarem experiências, perspectivas, ideias, métodos e técnicas, entre si, enriquecendo as suas obras e vidas.

\section{Após tantos anos em Paris, você já cogitou sobre um possível regresso definitivo à Guiné-Bissau, sua terra natal?}

Nos últimos anos, fui com muita frequência à Guiné-Bissau. Tenho projetos que gostaria de implementar na minha terra, e espero que o destino me dê a oportunidade de contribuir com algo mais concreto, de ser mais solidário com a minha gente, comprometido com a minha história (ancestralidade) e descendência.

Qual é a sua reflexão diante das manifestações, no mundo, contra a violência racial? É possível combater o racismo através das imagens, uma que, elas são formas de construir realidades?

Acredito que todos nós, artistas, temos a obrigação moral de chamar a atenção para a injustiça no mundo. O papel fundamental da criação artística é servir a algo. Não haverá algo mais nobre do que combater problemas que assolam a humanidade como o racismo, a desigualdade social, etc. Tais manifestações servem para erradicar o racismo, aquilo que não deveria existir. O racismo existe sim! Ele tem diferentes facetas que, às vezes, eu me questiono se aquilo que vejo é, ou não, o racismo. Não só os africanos, também os latinos, entre tantos outros povos, sofrem do racismo. Qualquer forma de racismo ou de desigualdade dentro da nossa sociedade não é tolerável. Deverá ser sempre, e, para sempre, um dever de todos nós, principalmente dos artistas, contribuir com seu saber e seu talento para que a seja uma história já vivida (passado). A erradicação é uma obrigação! 


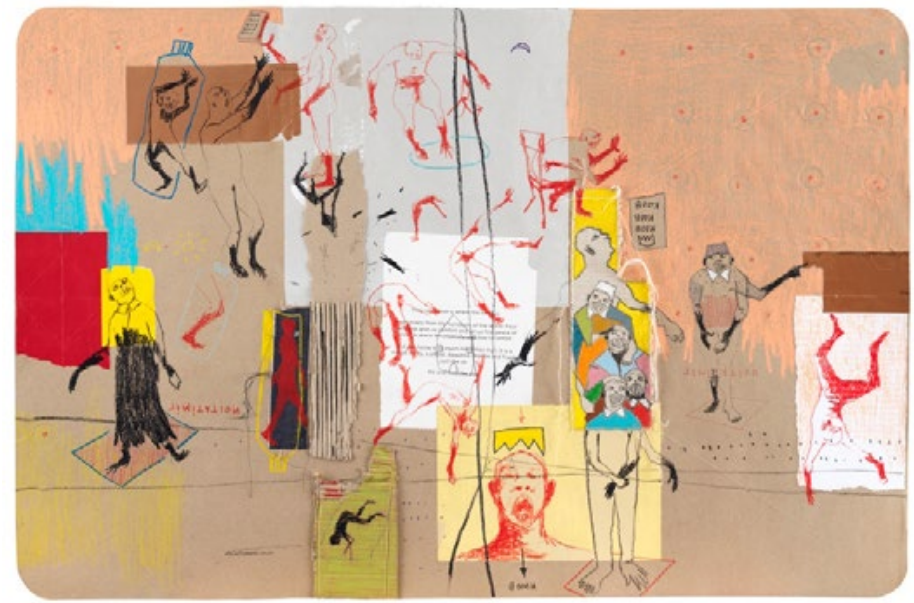

Figura 6: Nú Barreto, "Força", 2020, técnica: lápis cerâmica, giz pastel e colagem sobre papel reciclado, 77 × $117 \mathrm{~cm}$. Foto: Atelier 80/Paris (Cortesia: Nú Barreto \& Galerie Nathalie Obadia)

\section{O mundo completa um ano de pandemia, um período bastante angustiante e triste, que, afeta a sociedade em todas as estâncias, e, imagino que reflete também na sua poética. Como você vê a situação?}

Um aniversário doloroso que ainda deixa sequelas pelos quatro cantos do mundo. O horizonte é nublado e incerto! Creio que a única coisa que pode salvar o homem é a humanidade, a união e a solidariedade. Mas, a forma como a situação está sendo conduzida é caótica, o dinheiro se sobrepõe a tudo. Vivemos um problema comum e inédito em todos os países, em todas as sociedades, sem exceção. É a primeira vez na minha vida, e, suponho que na de todos, viver confinado. Paradoxalmente, o confinamento, não mudou a minha rotina, mas, as interdições pesaram muito. A vida do artista, é um confinamento, na medida em que, nada se cria sem isolamento. Neste período, desafiei-me a desenhar, tudo aquilo que eu sentia e via com relação a pandemia, um retrato com olhar interrogativo. O resultado foram três polípticos, cada um com 42 desenhos, que intitulei "Traços Diário I, II e III". Penso que quanto mais as expressões artísticas revelarem fatos, os homens corrigirão os atos. 


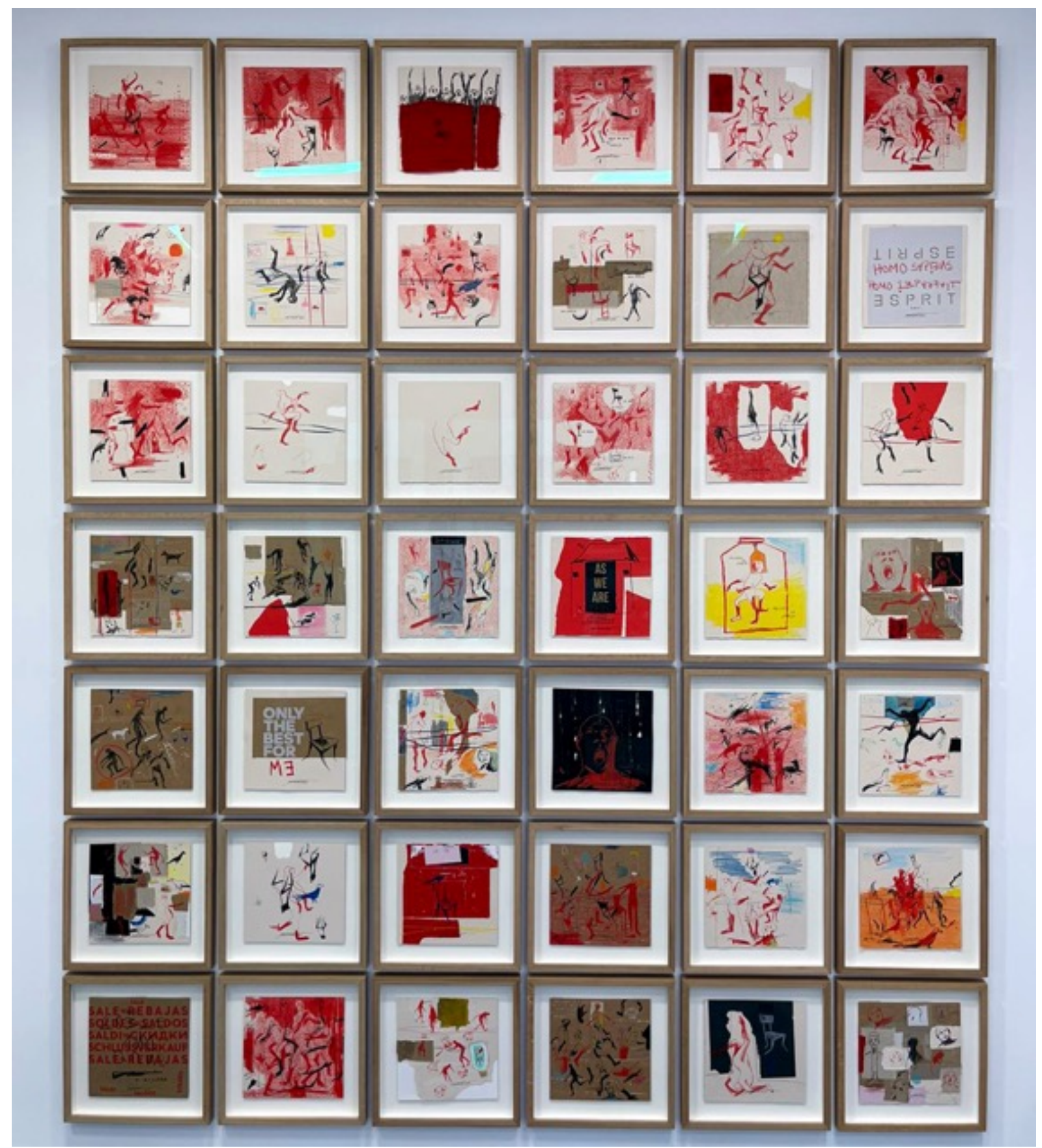

Figura 7: Nú Barreto, "Traços diário I", 2020, técnica: lápis cerâmica, caneta e colagem sobre papel, cada obra $30 \times 30 \mathrm{~cm}$ (com moldura $44 \times 44 \mathrm{~cm}$ ) x 42. Foto: Atelier 80/Paris (Cortesia: Nú Barreto \& Galerie Nathalie Obadia) 